\title{
COMPARATIVE ASSESSMENT OF STAINED-GLASS WINDOWS MATERIALS BY INFRARED
}

\section{THERMOGRAPHY}

\author{
Teresa Palomara,b*, Fernando Agua ${ }^{\mathrm{b}}$, Miguel Gomez-Heras ${ }^{\mathrm{c}, \mathrm{d}}$ \\ a Unidade de investigação VICARTE-Vidro e Cerâmica para as Artes, Campus de Caparica, FCT-UNL, Quinta da \\ Torre, 2829-516 Caparica, Portugal \\ b Instituto de Historia. Centro de Ciencias Humanas y Sociales, CSIC. Calle Albasanz, 26-28. 28037 Madrid \\ c Departamento de Geología y Geoquimica. Universidad Autonoma de Madrid. 28049 Madrid, Spain \\ d Instituto de Geociencias IGEO (CSIC,UCM), 28040 Madrid, Spain
}

${ }^{*}$ Corresponding author, e-mail: t.palomar@fct.unl.pt (T. Palomar)

\begin{abstract}
This paper reports the analyses of infrared thermography images of two stained-glass windows with the objective of the in-situ characterization of this type of artworks. The analyses were carried out by active thermography. The observations revealed that glasses absorbed the long-wave IR radiation emitted by the halogen lamps and their apparent surface temperature progressively increased. After switching the spotlight off, they experienced a progressive decrease of temperature. Silver stained glasses presented the same thermographic behavior than uncolored glasses because silver nanoparticles were too small or the yellow layer was too thin to produce a different response than the base glass with the IR radiation. The apparent surface temperature of enamels and grisailles depended on their thickness and color. Lead cames maintained an almost constant surface apparent temperature, except those painted that behave in a similar way than enamels. Metallic tin-lead welds experienced the most important variation of the surface apparent temperature in reflection mode due to the energy reflected by the surface of the weld. Glass defects such as big bubbles were also observed.
\end{abstract}

Keywords: Glass, grisaille, enamel, infrared thermography

This is the peer reviewed version of the following article: Palomar T, Agua F, Gómez-Heras M. Comparative assessment of stained-glass windows materials by infrared thermography. Int $\mathbf{J}$ Appl Glass Sci. 2018; 9: 530-539, which has been published in final form at https://doi.org/10.1111/ijag.12352. This article may be used for non-commercial purposes in accordance with Wiley Terms and Conditions for Use of Self-Archived Versions 


\section{Introduction}

Infrared (IR) thermography is a non-destructive and contactless technique which measures the IR radiation re-emitted from the measured targets. An IR camera produces apparent surface temperature images based on calculations from the received IR radiation and black body emission laws [1, 2]. The photo-thermal signal depends on parameters governing the heat diffusion: thermal conductivity, thermal emissivity, thermal diffusivity, temperature, specific heat, and density. In addition, these parameters can be correlated with the following characteristics of the object: aspects of the surface, presence of delamination, presence of cracks, internal structure of the material, progress of a physical and chemical transformation, drying and sedimentation, etc. Active thermography is a methodology for thermographic inspection in which the studied objects are thermally excited by an external heat source and the different thermal behaviors are analyzed mathematically using the Kirchhoff, Planck, and Boltzmann Laws and the different models of heat transfer. Conversely, passive thermography consists on the inspection of the object without being purposefully excited with an external heat source. The focus of this latter methodology is the location of thermal anomalies in the object based on a single image.

IR thermography has been used for more than 25 years to detect subjacent defects in buildings, such as fissures, cracks and humidity, as these features cause contrasting thermal responses. In cultural heritage, the most usual application of IR thermography is moisture location in historic buildings; other common applications in historic constructions are the assessment of previous conservation treatments such as cleanings, consolidations and restorations; and the identification of hidden structures behind the painting of the walls [3-16]. Frescos have been also widely studied with IR thermography to detect previous interventions, hidden damages and, in some cases, to discover the cause of their deterioration (humidity, unknown structures in the wall, etc.) [17-24]. In case of mosaics, IR thermography permits to evaluate the mortar and the suitability of the consolidative materials and treatments [24, 25]. The application of IR thermography is not only focused on constructions, it has been also applied on paintings on canvas or wood [26-29], tapestries [30], books [31, 32] and archaeological artifacts [33, 34] to evaluate their conservation state, to detect hidden damages and to improve their conservation strategies. However, studies on historical glasses are scarce and they are focused on the detection of grisaille detachments [34].

The main drawback for applying IR thermography on glasses is their behavior on the infrared region of the electromagnetic spectrum (wavelength in the range of $0.75-1000 \mu \mathrm{m}$ ). Silicate glasses are mostly 
transparent to solar radiation (short-wave infrared) and opaque to thermal radiation (mid- and long-wave infrared). This latter radiation is mostly absorbed, thereby heating up the glass. Much of the absorbed radiation is then re-radiated from the glass inward and outward [35]. This behavior favors that glasses seem opaque and cold in comparison with other building materials. Moreover, the high reflectance of glasses, mainly at incidence angles higher than 45 degrees, can produce erroneous temperature estimations [36, 37]. Nevertheless, IR thermography has been applied successfully to evaluate windows for industrial purposes [38-41], to research fire endurance of tempered glass [42], to study the mechanical defects and the elastic deformations on glass sheets [43-47], to analyze the efficiency of solar cells $[37,48]$ and to detect damages on fiber optics $[49,50]$.

Stained-glass windows are composed by glasses, which can be painted with enamels and grisailles, mounted on lead cames to form window panels. These cames are usually welded to each other using a melted tin-lead alloy. The characterization of these materials is commonly carried out during their restoration, when the panels are dismounted and transported to the workshop. The in-situ characterization with a non-destructive and contactless technique would be helpful to evaluate the conservation state of the stained-glass windows without being dismounted. The normal procedure for stained-glass windows assessment implies the mounting of scaffoldings and the observation piece by piece; however, the Stimulated Infra-Red Thermography (SIRT) permits the inspection of a wide surface in a very short period of time.

The main goal of this research was to assess for the first time the behavior of the different materials from the stained-glass windows (glasses, enamels, grisailles, lead cames and tin-lead welds) by passive and active infrared thermography with the future objective of the integration of this technique for usual analysis in the characterization of stained-glass windows.

\section{Materials and methods}

\subsection{Stained-glass windows}

Two different stained-glass windows were visualized by IR thermography: firstly, "Saint George and the dragon", a contemporary small size stained-glass window $(31 \times 31 \mathrm{~cm})$ from a Spanish private collection was analyzed (Fig. 1 a). The second stained-glass window analyzed was a $20^{\text {th }}$ century stained-glass window formed by three panels (158 $\times 460 \mathrm{~cm}$, each one) elaborated in the Maumejean workshop between 1942 and 1943 which represents the allegories of Sciences with a classic iconography. This stained-glass window is located in the building of the headquarters of the Spanish National Research 
Council (CSIC, Madrid) (Fig. 1 b). The window is placed with north orientation in a central courtyard of small dimensions, so it does not receive sunlight directly. Both stained-glass windows present different types of glasses, enamels and grisailles.
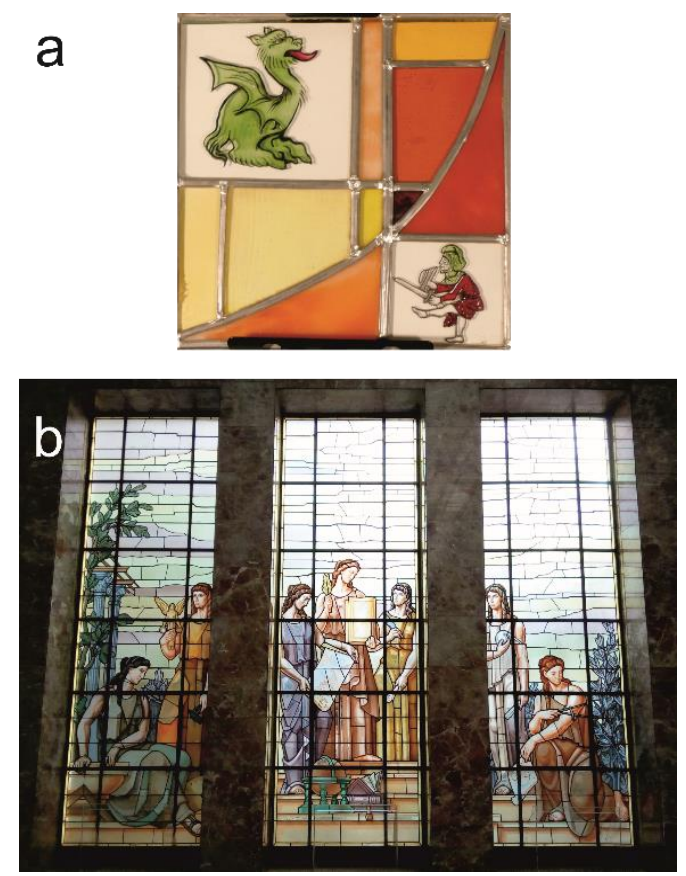

Fig. 1. Stained-glass window analyzed: a) "Saint George and the dragon" (Private collection, Spain), b) CSIC headquarters (Madrid, Spain) stained-glass window.

\subsection{IR thermography}

The characterization of the surface thermal behavior of glasses, enamels, grisailles, lead cames and tin-lead welds were carried out by infrared thermography. The thermographic analysis of both the stained-glass window entitled "Saint George and the dragon" and the $20^{\text {th }}$ century stained-glass window from the CSIC headquarters (Madrid, Spain) was carried out with a FLIR ThermaCAM ${ }^{\mathrm{TM}}$ B4. This is a LWIR (Long-wave Infrared) Camera with 7.5 to $13 \mu \mathrm{m}$ IR wavelength detection range, which corresponds to a -20 to $+130{ }^{\circ} \mathrm{C}$ temperature detection range. Temperature accuracy is $0.08{ }^{\circ} \mathrm{C}$ and the

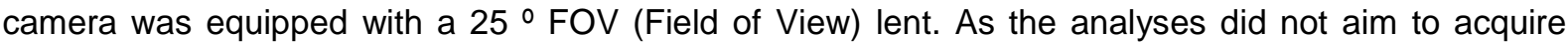
accurate temperature measurements but to detect thermal anomalies and perform active thermography calculations, emissivity was set to a constant value (0.96) in both transmission and reflection modes. The camera was set at $1 \mathrm{~m}$ distance. For thermal excitation, two 500-watt halogen lamps located at 1 $\mathrm{m}$ from the glass were used. The acquisition lasted $20 \mathrm{~min}: 10 \mathrm{~min}$ during heating and 10 minutes cooling after turning off the heating source with a frequency of acquisition of one capture per minute. "Saint 
George and the dragon" glass window was analyzed in the laboratory in February 2012, being room temperature around $20{ }^{\circ} \mathrm{C}$ throughout the experiment and the $20^{\text {th }}$ century stained-glass window was analyzed on site in the CSIC headquarters (Madrid, Spain) in August 2011, being room temperature around $30^{\circ} \mathrm{C}$.

In addition to the apparent surface temperature evolution of discrete pixels with time, Principal Components of Thermography (PCT) analyses were performed.

PCT analyses were made on each of the series of images recorded at equal times. The surface apparent temperature of each pixel in these series of images is a function of space and time. PCT analyses are based on searching linear combination of images within the series that diagonalize the covariance matrix (i.e. the matrix representing the covariances of temperature-time, temperature-space and time-space). The result of each linear combination is another image that is called PCT, with an associated eigenvalue. The larger the eigenvalue of a certain combination, the larger is the contribution to the total variance of the process. The linear combination of images contributing the most to the total variance is the PCT-1 component and in descending order of contribution PCT-2, PCT-3, etc.

In each PCT image, the scale represents the covariance; therefore darker (lower) negative values indicate areas with a negative covariance in relation to that specific component. The set of PCT allows categorizing what areas of the object are being affected more than others are by the thermal excitation as well as recognize the contribution of different processes in the thermal excitation (materials, defect, etc.) By analyzing each PCT areas behaving analogously in relation to a process can be recognized. PCT images were obtained through the application ir_view (v. 1.7.5) developed with Matlab [51]. PCT analyses have been used previously to analyze materials in heritage buildings [52-54], but have not been performed previously for glass windows.

The color of the glasses was measured with the portable colorimeter "Blue line" CM-310 from Metrotec in reflective light mode placing the white standard under the analyzed area.

\section{Results}

\subsection{Analyses of the evolution of the apparent surface temperature}

\subsubsection{Glasses}

Glasses are almost transparent to short-wave IR radiation, but they are opaque to mid- and long-wave IR radiation [35]. Usual halogen lamps, as used in this study, emit from 0.35 to $4-5 \mu \mathrm{m}$ depending on the filament, with the maximum emission around $1.0 \mu \mathrm{m}[55,56]$. The transmittance of glasses to 
radiations from $0.3 \mu \mathrm{m}$ up to $2.5 \mu \mathrm{m}$ is around 0.9 and the reflection is around 0.07 , which means that they are practically transparent to the radiation [36]. Nevertheless, the glass transmittance for radiations with wavelengths between 2.5-4.0 $\mu \mathrm{m}$ decrease to $\sim 0.4$, and for wavelengths higher than $5.0 \mu \mathrm{m}$ the transmittance is almost null $[36,57]$. The wavelength range of the thermographic camera $(7.5$ to $13 \mu \mathrm{m})$ coincides with the absorption bands of the bridging and non-bridging Si-O bonds [58]. This radiation is absorbed by the glasses, heating them up.

According to this fact, the behavior of glasses of the stained-glass windows depended on the thermographic mode applied (Fig. 2 a). In transmission mode, glasses presented a significant increase in their surface apparent temperature due to the heating induced by the absorption of the silicate bands, and also due to the radiation transmission through them. However, in reflection mode, glasses showed the increase of the surface apparent temperature due to the warming of the glass surface and the reflection of the IR radiation. The heating was more intense in transmission mode than in reflection mode because of the higher influence of the lamp radiation, which depended on the distance of the camera. Therefore the cooling, when the spotlight was switched off, was slower in reflection mode (Fig. 2 b). 

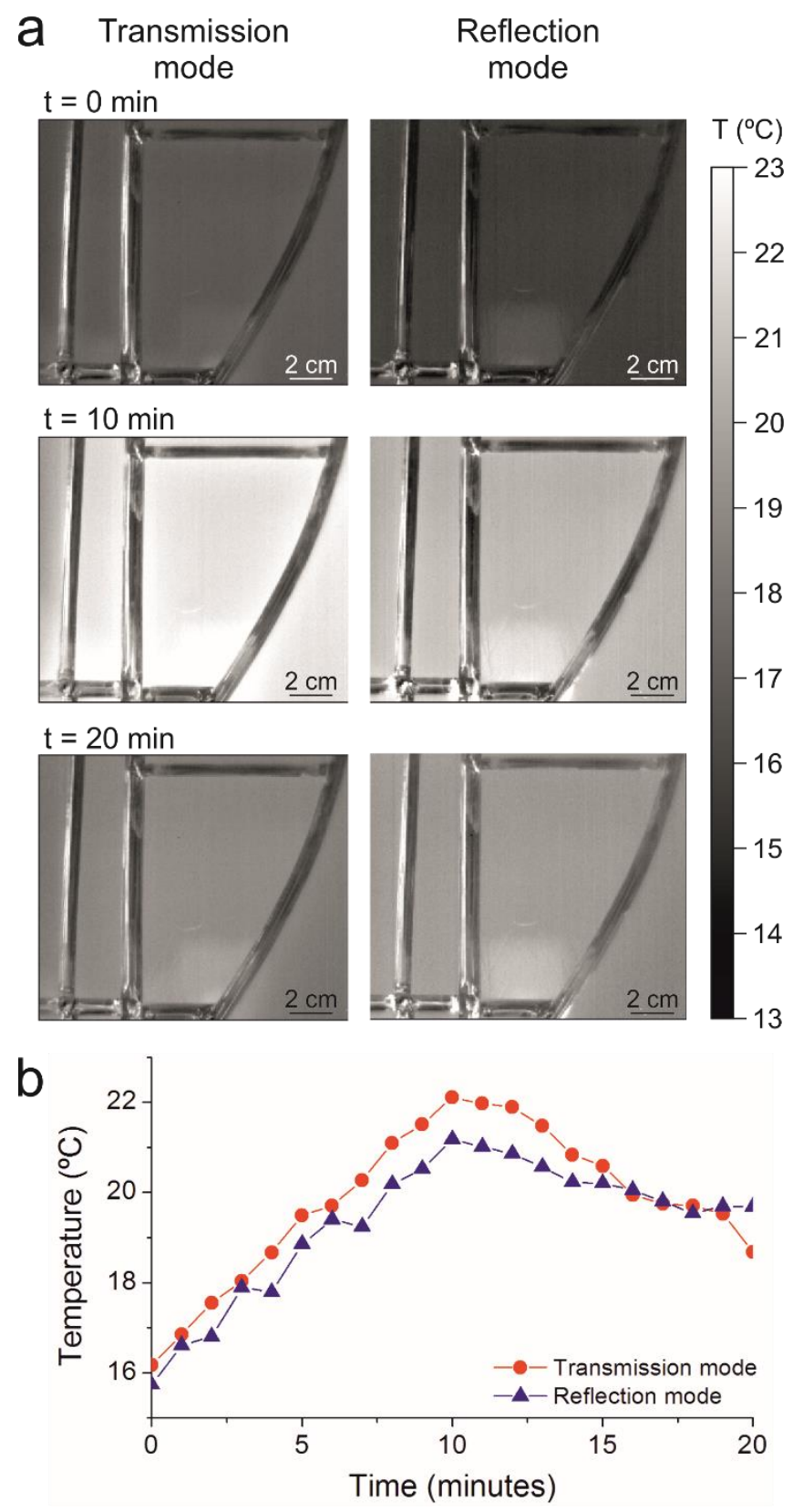

Fig. 2. a) Surface apparent temperature map evolution in transmission and reflection mode at 0,10 and 20 minutes of essay in "Saint George and the dragon" (Private collection, Spain). b) Thermal variations of an orange glass in transmission and reflection mode.

\subsubsection{Silver stained glasses}

The stained-glass window "Saint George and the dragon" presents three silver stained glasses with different yellow tones. Historically this coloration was obtained applying a mixture of silver salts, clays or ochres, water and Arabic rubber on one of the glass surfaces and firing them at temperatures between 500 and $650^{\circ} \mathrm{C}$. During firing, silver cations penetrate into the glass by ion exchange with the sodium or potash cations, and then are reduced to their metallic state nucleating into clusters. The final color of the glass varies from pale yellow to dark orange and it depends on the oven temperature, the firing time, 
the type of paint and even the glass composition because these parameters influence the size, shape and distribution of the silver nanoparticles [59-61].

Despite their different coloration (CIE- $L^{*} a^{*} b^{*}$ coordinates of Yellow1: $L^{*}=72.98 ; a^{*}=-2.01 ; b^{*}=34.03$; Yellow2: $L^{*}=85.59 ; a^{*}=7.95 ; b^{*}=37.88 ;$ Yellow3: $\left.L^{*}=53.13 ; a^{*}=-4.98 ; b^{*}=55.71\right)$, the three silver stained glasses presented a thermographic behavior similar to the base glass because silver nanoparticles were too small or the yellow layer was too thin to produce a different response than the base glass with the IR radiation (Fig. 3).

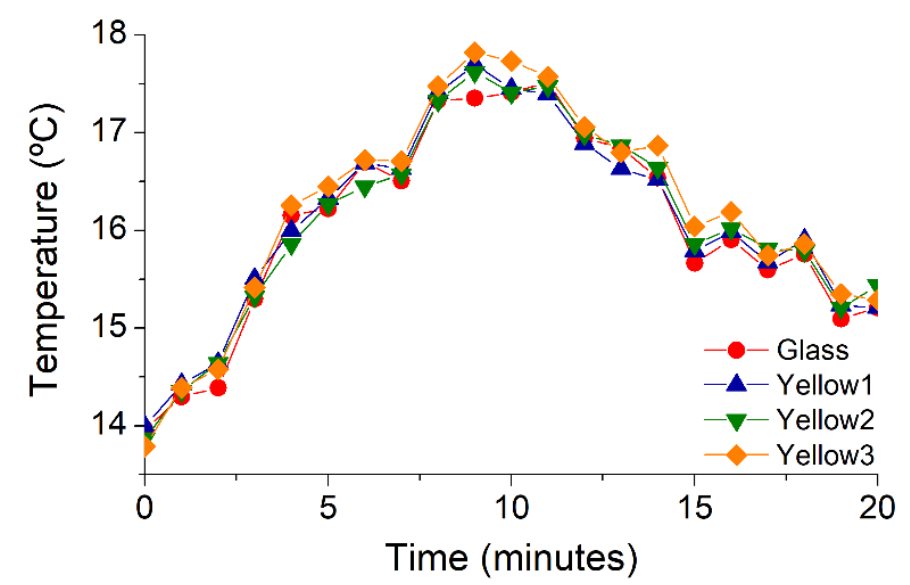

Fig. 3. Thermal variations in "Saint George and the dragon" (Private collection, Spain) measured in reflection mode of uncolored glass and yellow silver glasses.

\subsubsection{Enamels}

An enamel is a brightly colored glass formed by a highly fusible glass with a small amount of pigment. The powdery enamel is applied onto the glass pane with a brush and then fired. The result is a thin homogeneous layer of glass of a bright color on the glass surface [62, 63]. Enamels present different colors depending on their thickness and colorants, and could be transparent or translucent depending on the firing regime.

During the illumination with the halogen lamps, the areas painted with enamels experienced a higher increase of their surface apparent temperature in comparison with the glass support (Fig. 4). 


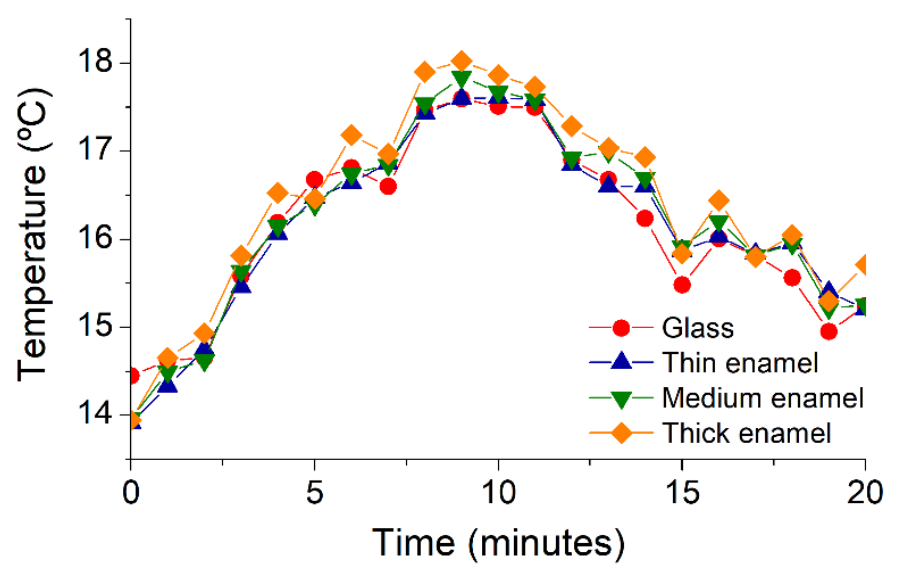

Fig. 4. Thermal variations in "Saint George and the dragon" (Private collection, Spain) measured in reflection mode of a glass without surface layer and glasses painted with a thin, medium and thick layer of orange enamel.

A relation between the thickness of the enamel layer and the surface temperature was observed. The surface apparent temperature of the glasses painted with the thin layer of enamel showed a similar behavior than glasses without surface layer (Fig. 4). However, those glasses painted with thicker layers from the same orange enamel presented slightly higher surface apparent temperatures (Fig. 4). This behavior is probably related to the low transmittance of glassy materials to mid- and long-wave IR radiation which induced the heating of the surface layers.

The second variable which modifies the surface apparent temperature of the enamels is their color. For opaque materials, light colors present a higher reflectance than dark colors [35]. The enamels presented the same behavior. Enamels with darker colors increased more the surface apparent temperature in comparison with those ones with lighter colors (Fig. $5 \mathrm{a}$ and b). The areas without enamels showed the lower increase in temperature. 


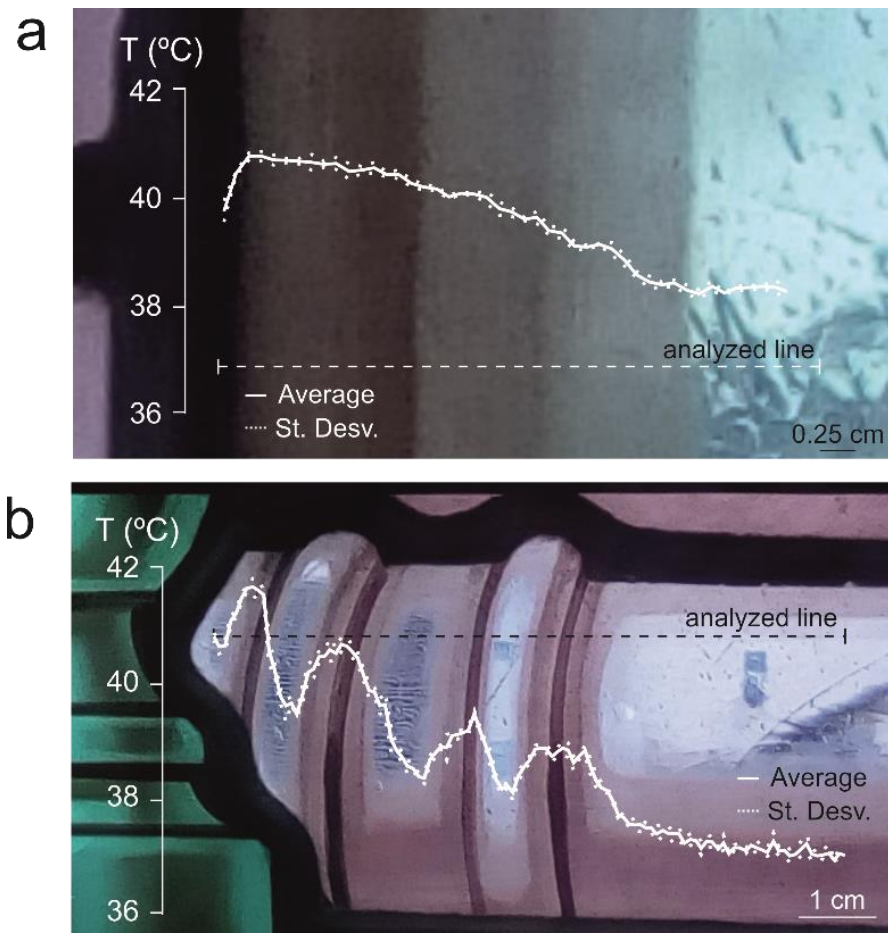

Fig. 5. a, b) Linear thermal variation in the stained-glass window from the CSIC headquarters (Madrid, Spain) measured in reflection mode after 10 minutes of irradiation (Average of 3 pixels in vertical).

\subsubsection{Grisailles}

A grisaille is a dark paint applied to draw the contours and details of the figures and to produce the effect of shades and volumes. Grisailles are made by powdering a highly fusible glass with pigments such as iron oxide, but it also often contains copper, tin, and/or manganese oxides. During firing the grains of fusible glass melt and fix the pigment grains onto the glass surface [62, 64]. They usually present dark colors such as black or brown.

Grisailles showed the most important increase of surface apparent temperature during the illumination because of their lower albedo, and subsequent higher absorption of thermal radiation (Fig. 6 a and b). A similar effect was observed in a glass piece with grisaille from the French Cathedral of "Chartres" analyzed by photothermal analysis [34].

In the glass decorated with a dragon, the area with the highest temperature increase was the wing and the neck on the dragon because there was a higher concentration of grisaille lines. In addition, they can also affect the surrounding elements increasing their surface apparent temperature. 


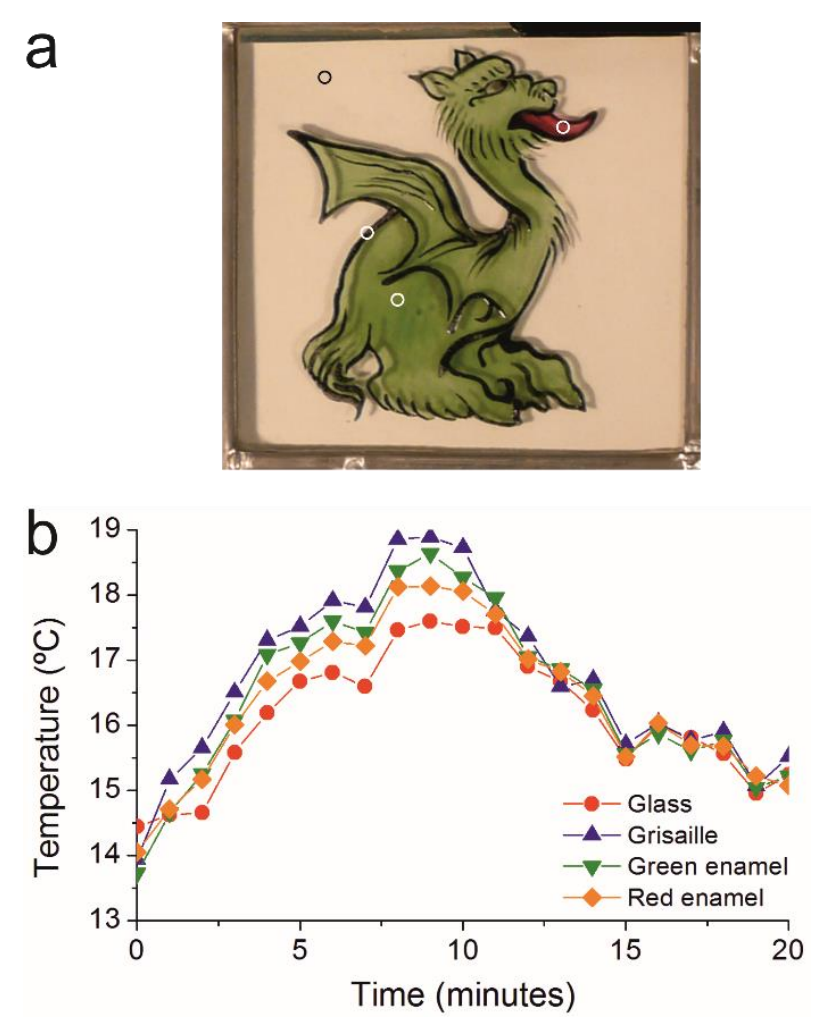

Fig. 6. a) Detail of "Saint George and the dragon" (Private collection, Spain). b) Thermal variations of glass, grisaille, green enamel and red enamel in reflection mode (from the points indicated in the Fig. 6 a).

\subsubsection{Metallic materials}

Metallic materials presented a completely different thermal behavior. In transmission mode, the low heat capacity of metals produced an almost constant surface apparent temperature (Fig. 2 a). In reflection mode, the lead cames showed a slight temperature rise because the emissivity coefficient of nonoxidized lead is $0.057-0.075$ [65], while tin-lead welds presented an important increase of the surface apparent temperature $\left(\sim 40^{\circ} \mathrm{C}\right)$ mainly due to the reflection of the energy emitted by the halogen lamp on the fire-polished surface of the welds (Fig. 7 a).

The $20^{\text {th }}$ century stained-glass window presented the metallic parts painted black, and their behavior was similar to dark enamels (Fig. 7 b). 

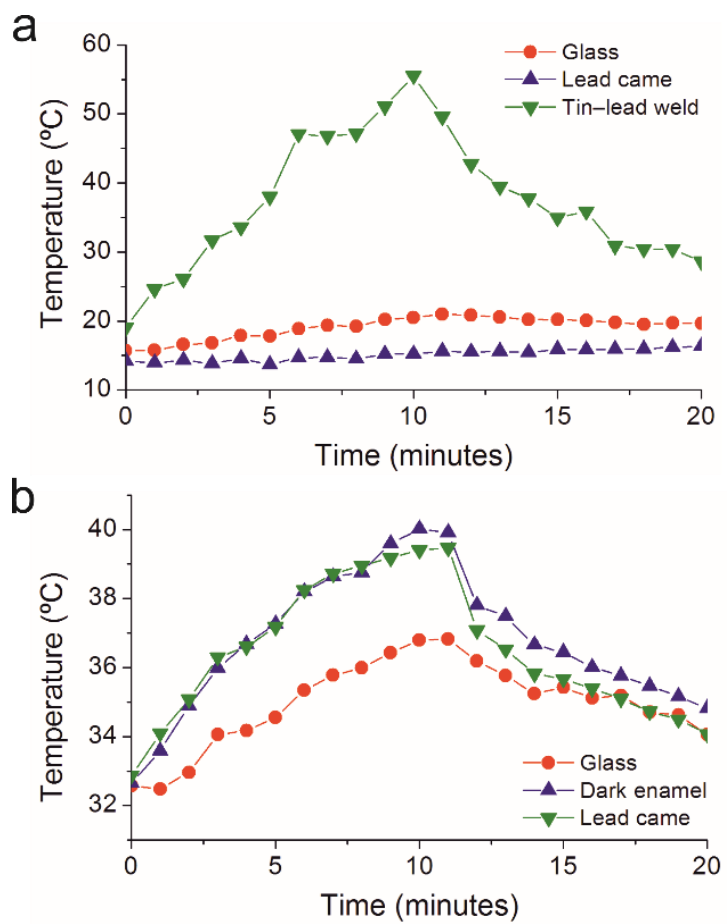

Fig. 7. a) Thermal variations in "Saint George and the dragon" (Private collection, Spain) measured in reflection mode of a glass, lead came and tin-lead weld. b) Thermal variations in the stained-glass window from the CSIC headquarters (Madrid, Spain) measured in reflection mode of a glass, dark enamel and painted lead came.

The metallic frame also induces an increase in the surface temperature from the border of the glass to the center contrary to the windows with wood frame [38]. This different effect could be due to the different transmission of the heat in the frames.

\subsubsection{Glass defects}

Infrared thermography was also applied to identify defects on glasses such as bubbles. They were observed without illumination and after 10 minutes of irradiation in transmission and reflection mode. Large bubbles were better observed without artificial illumination due to the reflection of the environmental IR radiation in the irregularities of the glass surface because, after illumination, the glass surface was heated and it masked the bubble (Fig. 8). According to Campa et. al [66], bubbles can increase more the surface temperature during the heating, however, in this case, the glass hide it. 

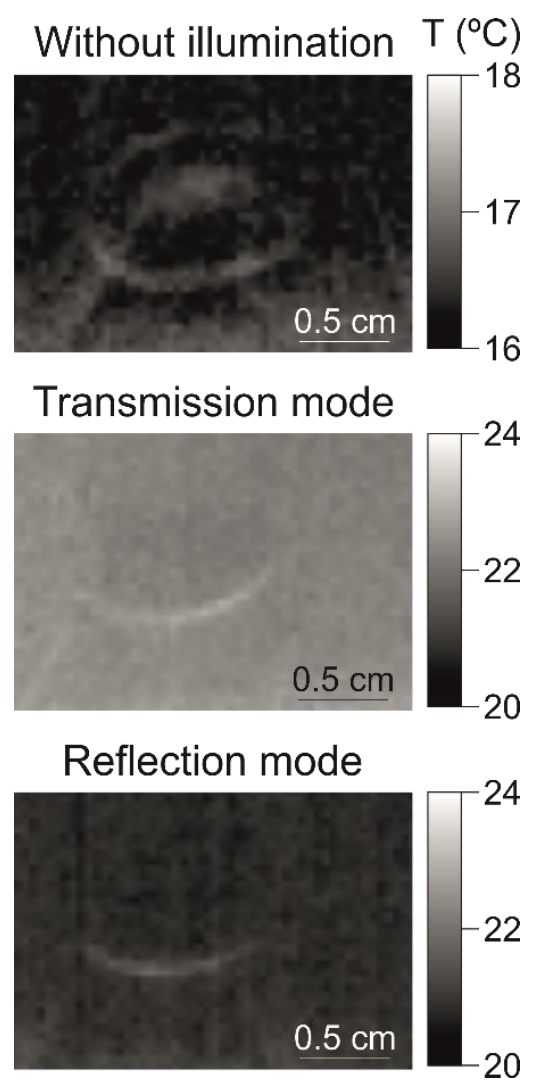

Fig. 8. A large bubble in the glass observed by IR thermography without illumination and after 10 minutes in transmission and reflection mode.

\subsection{Principal Components of Thermography analyses}

The PCT analysis was applied to the thermography images obtaining the percentage of contribution to the total covariance in each case (Figs. 9, 10 and 11). All images showed extreme positive and negative values corresponding to the reflective behavior of the lead cames (Figs. 9 a, 10 a and $11 \mathrm{a}$ ), which need to be excluded from the image analyses that will focus only on glass. In the series of images, PCT-1 shows most of the information, being PCT-2 and PCT-3 redundant or lacking any sort of information. The exception would be a pattern revealed in the PCT-3 from the book spine detail (Fig. $10 \mathrm{c}$ ) which could be a different reflection of the glass surface or may be associated to a thickening of the putty beneath.

In the 1940's stained-glass window from the CSIC headquarters (Madrid, Spain), the painted glasses were the areas which showed higher values of covariance (lighter colors) as opposed to unpainted glass (dark colors) and a correlation between the thickness of the enamel and contribution to the total covariance can be observed (Fig. 9 and 10). 
In the case of the contemporary panel, the factor affecting the most to the total variation of the series of images was the presence of grisailles, which were accurately observed in the PCT-1 image (Fig. 11 a). The presence of the red and green enamels used in the dragon and the knight was observed in the PTC-2. However, the orange enamels, which covered some of the glass pieces, did not show an especial response on the PCT analyses.

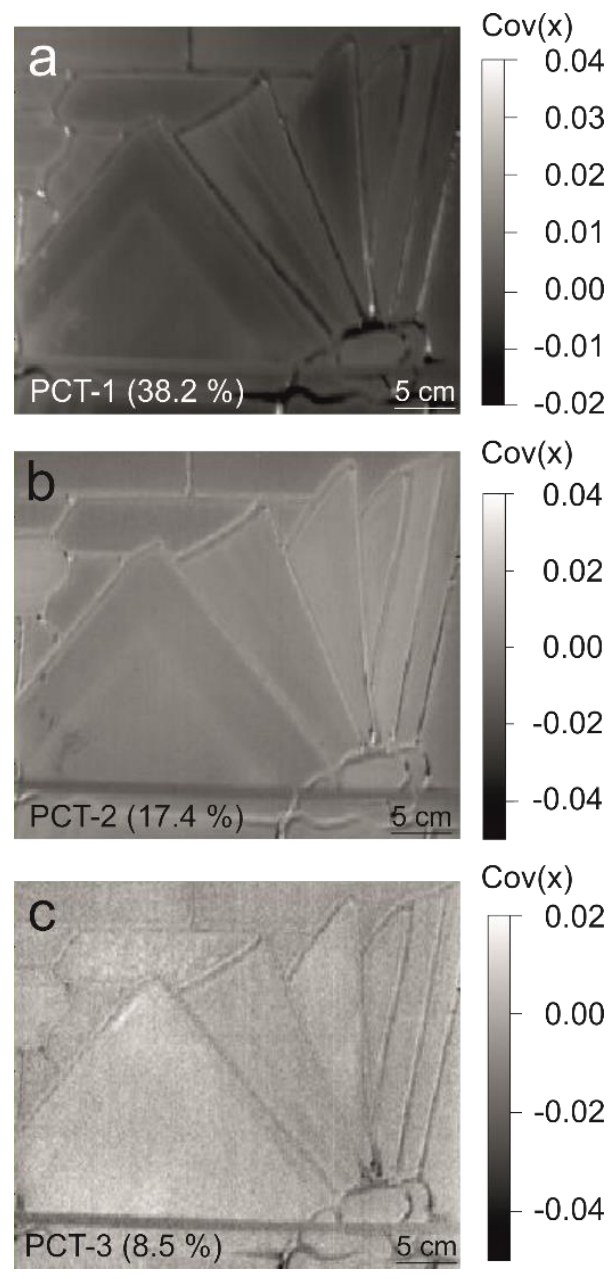

Fig. 9. Principal components of thermography analyses of the open book detail in the $20^{\text {th }}$ century stained-glass window (Madrid, Spain) in reflection mode. a) PCT-1, b) PCT-2, c) PCT-3. 


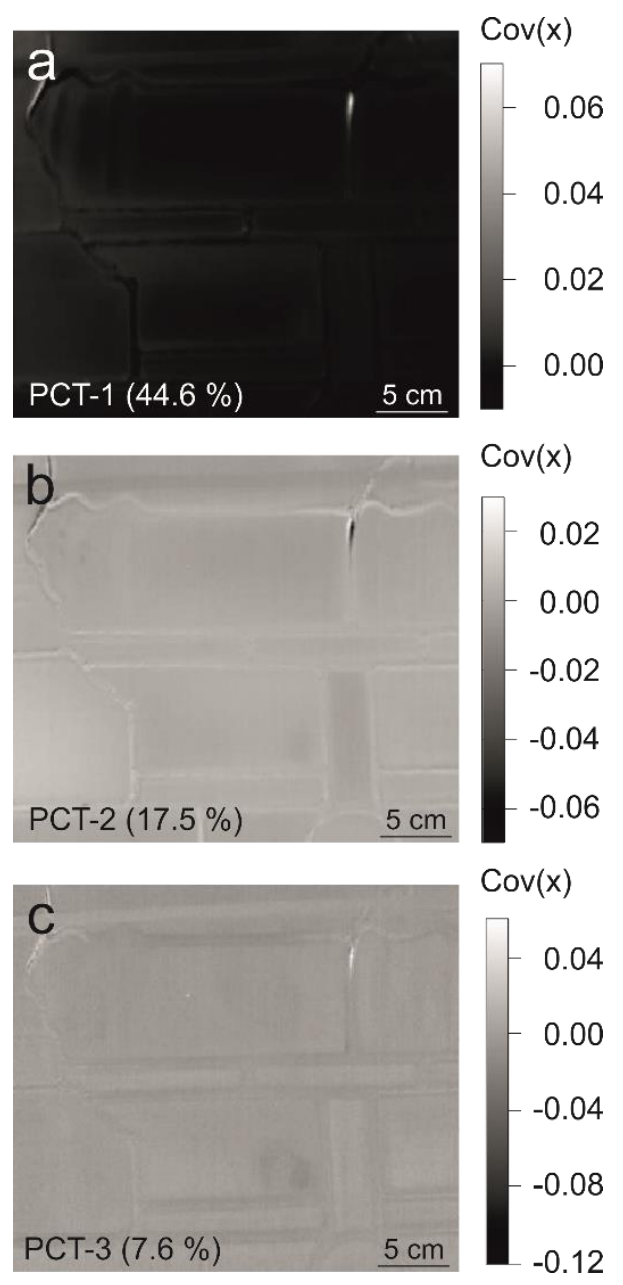

Fig. 10. Principal components of thermography analyses of the book spine detail in the $20^{\text {th }}$ century stained-glass window (Madrid, Spain) in reflection mode. a) PCT-1, b) PCT-2, c) PCT-3. 

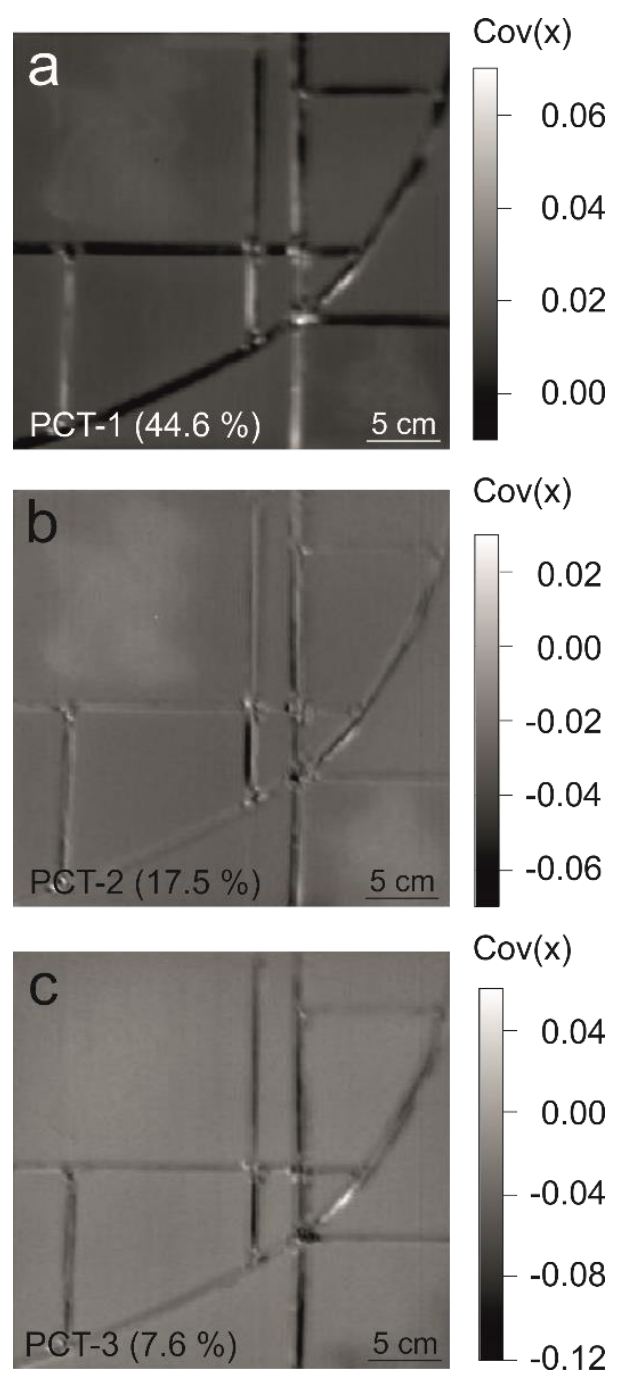

Fig. 11. Principal components of thermography analyses of the small stained-glass window (Private collection, Spain) in reflection mode. a) PCT-1, b) PCT-2, c) PCT-3.

\section{Conclusions}

Two stained-glass windows were successfully characterized with infrared thermography. Each material showed a different behavior. Glasses were heated due to the absorption of the mid- and long-wave IR radiation emitted by the halogen lamps which lead a progressively increase of apparent surface temperature followed by a progressive decrease after switching the spotlight off. In transmission mode, the apparent surface temperature is higher due to the transmission of the radiation through them. Silver stained glasses presented the same thermographic behavior than base glasses because silver nanoparticles were too small or the yellow layer was too thin to produce a different response than the base glass with the IR radiation. Enamels and grisailles experienced a higher increase of their surface apparent temperature in comparison with the glass support, which depended on the thickness, and color 
of the surface layer. Metallic materials presented an almost constant surface apparent temperature in transmission mode due to its low heat capacity; although in reflective mode the energy reflected by the surface of the metal induced the fictitious increase of the surface apparent temperature. The thermal behavior of metal was different when they were painted; then, their behavior was similar to enamels. Glass defects such as big bubbles were also detected by infrared thermography. PCT analysis of thermal images proved to be successful in detecting the influence of paintings and grisailles in the thermal response of glass windows. The differences between the behavior of early $20^{\text {th }}$ century glass windows in relation to contemporary one may be a result from the evolution of composition and techniques, as painting and its thickness is the main factor affecting the thermal response in 1940's glass windows, while grisailles (and not enamels) are the main driving factor for change in contemporary glass windows. The complementary study with metrology could analyze the real temperature of the surface and not only apparent temperature; however, IR thermography has proved to be a useful tool for the in-situ analysis of historical stained glass windows.

\section{Acknowledgements}

The authors are indebted to the Research Group Cervitrum (CCHS-CSIC), the Subdirección General de Obras e Infraestructuras (CSIC, María del Carmen González Peñalver) and the Servicio de Patrimonio (CSIC, José Antonio Ocaña Martínez), for providing official permissions, access, and kind cooperation to carry out this scientific research. They also acknowledge the partial funding of the Fundação para a Ciência e a Tecnologia from Portugal (Project ref. UID/EAT/00729/2013 and Postdoctoral grant ref. SFRH/BPD/108403/2015) and the research program GEOMATERIALES 2-CM Program Ref. S2013/MIT-2914 from the Community of Madrid. Finally, the authors wish to mention the professional support of the Spanish TechnoHeritage network.

\section{References}

[1] Kylili A, Fokaides PA, Christou P, Kalogirou SA. Infrared thermography (IRT) applications for building diagnostics: A review. Appl. Energ. 2014; 134: 531-549. http://dx.doi.org/10.1016/i.apenergy.2014.08.005

[2] Bagavathiappan S, Lahiri BB, Saravanan T, Philip J, Jayakumar T. Infrared thermography for condition monitoring - A review. Infrared Phys. Techn. 2013; 60: 35-55. http://dx.doi.org/10.1016/.infrared.2013.03.006

[3] Avdelidis NP, Moropoulou A. Applications of infrared thermography for the investigation of historic structures. J. Cult. Herit. 2004; 5 (1): 119-127. http://dx.doi.org/10.1016/i.culher.2003.07.002 
[4] Bisegna F, Ambrosini D, Paoletti D, Sfarra S, Gugliermetti F. A qualitative method for combining thermal imprints to emerging weak points of ancient wall structures by passive infrared thermography A case study. J. Cult. Herit. 2014; 15 (2): 199-202. http://dx.doi.org/10.1016/j.culher.2013.03.006

[5] Balaras CA, Argiriou AA. Infrared thermography for building diagnostics. Energ. Buildings 2002; 34 (2): 171-183. http://dx.doi.org/10.1016/S0378-7788(01)00105-0

[6] Costanzo A, Minasi M, Casula G, Musacchio M, Buongiorno M. Combined use of terrestrial laser scanning and IR thermography applied to a historical building. Sensors 2015; 15 (1): 194. http://dx.doi.org/10.3390/s150100194

[7] Litti G, Khoshdel S, Audenaert A, Braet J. Hygrothermal performance evaluation of traditional brick masonry in historic buildings. Energ. Buildings 2015; 105: 393-411. http://dx.doi.org/10.1016/j.enbuild.2015.07.049

[8] Kandemir-Yucel A, Tavukcuoglu A, Caner-Saltik EN. In situ assessment of structural timber elements of a historic building by infrared thermography and ultrasonic velocity. Infrared Phys. Techn. 2007; 49 (3): 243-248. http://dx.doi.org/10.1016/j.infrared.2006.06.012

[9] Moropoulou A, Avdelidis NP, Koui M, Delegou ET, Tsiourva T. Infrared thermographic assessment of materials and techniques for the protection of cultural heritage. In: Proc. SPIE 4548, Multispectral and Hyperspectral Image Acquisition and Processing, eds. Q. Tong, Y. Zhu and Z. Zhu. Wuhan, China; 2001: 313-318. http://dx.doi.org/10.1117/12.441418

[10] Moropoulou A, Apostolopoulou M, Moundoulas P, Karoglou M, Delegou E, Lampropoulos K, et al. The combination of NDTS for the diagnostic study of historical buildings: The case of Kaisariani monastery. In: Proceedings of the COMPDYN 2015 - 5th ECCOMAS Thematic Conference on Computational Methods in Structural Dynamics and Earthquake Engineering; 2015: 2321-2336.

[11] Imposa S. Infrared thermography and Georadar techniques applied to the "Sala delle Nicchie" (Niches Hall) of Palazzo Pitti, Florence (Italy). J. Cult. Herit. 2010; 11 (3): 259-264. http://dx.doi.org/10.1016/j.culher.2009.04.005

[12] Morillas H, García-Galan J, Maguregui M, García-Florentino C, Marcaida I, Carrero JA, et al. In-situ multianalytical methodology to evaluate the conservation state of the entrance arch of La Galea Fortress (Getxo, north of Spain). Microchem. J. 2016; 128: 288-296. http://dx.doi.org/10.1016/i.microc.2016.05.010

[13] Rainieri C, Marra A, Rainieri GM, Gargaro D, Pepe M, Fabbrocino G. Integrated non-destructive assessment of relevant structural elements of an Italian heritage site: the Carthusian monastery of Trisulti. J. Phys. Conf. Ser. 2015; 628 (1): 012018 (012011-012018).

[14] Pérez-Sánchez JC, Piedecausa-García B. Cúpulas de crucero en templos de la provincia de Alicant (s.XVII-XIX): construcción y geometría. Inf. Constr. 2015; 67 (538): e077(071-010). http://dx.doi.org/10.3989/ic.13.176

[15] Rodríguez Liñán C, Morales Conde MJ, Rubio de Hita P, Pérez Gálvez F. Inspección mediante técnicas no destructivas de un edificio histórico: Oratorio San Felipe Neri (Cádiz). Inf. Constr. 2011; 63 (521): 13-22. http://dx.doi.org/10.3989/ic.10.032

[16] Li Z, Yao W, Lee S, Lee C, Yang Z. Application of infrared thermography technique in building finish evaluation. J. Nondestruct. Eval. 2000; 19 (1): 11-19. http://dx.doi.org/10.1023/a:1006612023656

[17] Vettori S, Bracci S, Cantisani E, Riminesi C, Sacchi B, D'Andria F. A multi-analytical approach to investigate the state of conservation of the wall paintings of Insula 104 in Hierapolis (Turkey). Microchem. J. 2016; 128: 279-287. http://dx.doi.org/10.1016/j.microc.2016.05.006

[18] Giovannacci D, Detalle V, Martos-Levif D, Ogien J, Bernikola E, Tornari V, et al. Case study of Sainte-Marie Chapel, Fontaine Chaalis (France): complementarity of different optical techniques. In: Proc. SPIE 9527, Optics for Arts, Architecture, and Archaeology V, eds. L. Pezzati and P. Targowski. Munich, Germany; 2015: 95270L (95271-95279). http://dx.doi.org/10.1117/12.2184600

[19] Bison P, Bortolin A, Cadelano G, Ferrarini G, López F, Maldague X. Comparison of image processing techniques for the on-site evaluation of damaged frescoes. In: Proc. SPIE 9105, Thermosense: Thermal Infrared Applications XXXVI, eds. F. P. Colbert and S.-J. Hsieh. Baltimore, Maryland, USA; 2014: 91050E (91051-91058). http://dx.doi.org/10.1117/12.2053782

[20] De Fino M, Fatiguso F, Scioti A, De Tommasi G. Non destructive investigation for historic documentation and construction qualification of monumental buildings: The case of S. Gregory Church in Bari, South Italy. In: Structural Studies, Repairs and Maintenance of Heritage Architecture XIII, eds. C. A. Brebbia. Southampton, UK: WIT Press; 2013: 99-110. http://dx.doi.org/10.2495/STR130091

[21] Ludwig N, Rosina E. Dynamic IRT for the frescoes assessment: the study case of Danza Macabra in Clusone (Italy). In: Proc. SPIE 5782, Thermosense XXVII, eds. G. R. Peacock, D. D. Burleigh and J. J. Miles. Orlando, Florida, USA; 2005: 272-279. http://dx.doi.org/10.1117/12.604648

[22] Sfarra S, Theodorakeas P, Ibarra-Castanedo C, Avdelidis NP, Ambrosini D, Cheilakou E, et al. How to Retrieve Information Inherent to Old Restorations Made on Frescoes of Particular Artistic Value Using 
Infrared Vision? Int. J. Thermophys. 2015; 36 (10): 3051-3070. http://dx.doi.org/10.1007/s10765-015$1962-8$

[23] Kordatos EZ, Exarchos DA, Stavrakos C, Moropoulou A, Matikas TE. Infrared thermographic inspection of murals and characterization of degradation in historic monuments. Constr. Build. Mater. 2013; 48: 1261-1265. http://dx.doi.org/10.1016/i.conbuildmat.2012.06.062

[24] Carlomagno GM, Carosena M. Infrared thermography in the restoration of cultural properties. In: Proc. SPIE 4360, Thermosense XXIII, eds. A. E. Rozlosnik and R. B. Dinwiddie. Orlando, Florida, USA; 2001: 203-216. http://dx.doi.org/10.1117/12.420992

[25] Moropoulou A, Bakolas A, Karoglou M, Delegou ET, Labropoulos KC, Katsiotis NS. Diagnostics and protection of Hagia Sophia mosaics. J. Cult. Herit. 2013; 14 (3, Supplement): e133-e139. http://dx.doi.org/10.1016/i.culher.2013.01.006

[26] Sfarra S, Ibarra-Castanedo C, Ambrosini D, Paoletti D, Bendada A, Maldague X. Defects detection and non-destructive testing (NDT) techniques in paintings: a unified approach through measurements of deformation. In: Proc. SPIE 8790, Optics for Arts, Architecture, and Archaeology IV, eds. L. Pezzati and P. Targowski. Munich, Germany; 2013: 87900G (87901-87915). http://dx.doi.org/10.1117/12.2019881

[27] Gavrilov D, Maeva E, Grube O, Vodyanoy I, Maev R. Experimental comparative study of the applicability of infrared techniques for non-destructive evaluation of paintings. J. Am. Inst. Conserv. 2013; 52 (1): 48-60. http://dx.doi.org/10.1179/0197136012Z.0000000002

[28] Sfarra S, Theodorakeas P, Ibarra-Castanedo C, Avdelidis NP, Paoletti A, Paoletti D, et al. Importance of integrated results of different non-destructive techniques in order to evaluate defects in panel paintings: the contribution of infrared, optical and ultrasonic techniques. In: Proc. SPIE 8084, O3A: Optics for Arts, Architecture, and Archaeology III, Munich, Germany 2011: 80840R (80841-80813). http://dx.doi.org/10.1117/12.889335

[29] Ambrosini D, Daffara C, Di Biase R, Paoletti D, Pezzati L, Bellucci R, et al. Integrated reflectography and thermography for wooden paintings diagnostics. J. Cult. Herit. 2010; 11 (2): 196-204. http://dx.doi.org/10.1016/i.culher.2009.05.001

[30] Dulieu-Barton JM, Sahin M, Lennard FJ, Eastop DD, Chambers AR. Assessing the feasibility of monitoring the condition of historic tapestries using engineering techniques. Key Eng. Mat. 2007; 347: 187-192. http://dx.doi.org/10.4028/www.scientific.net/KEM.347.187

[31] Doni G, Orazi N, Mercuri F, Cicero C, Zammit U, Paoloni S, et al. Thermographic study of the illuminations of a 15th century antiphonary. J. Cult. Herit. 2014; 15 (6): 692-697. http://dx.doi.org/10.1016/j.culher.2013.12.001

[32] Riccardi A, Mercuri F, Paoloni S, Zammit U, Marinelli M, Scudieri F. Parchment ageing study: New methods based on thermal transport and shrinkage analysis. E-Pres. Sci. 2010; 7: 87-95.

[33] Mercuri F, Zammit U, Orazi N, Paoloni S, Marinelli M, Scudieri F. Active infrared thermography applied to the investigation of art and historic artefacts. J. Therm. Anal. Calorim. 2011; 104 (2): 475-485. http://dx.doi.org/10.1007/s10973-011-1450-8

[34] Candoré JC, Bodnar JL, Detalle V, Grossel P. Non-destructive testing of works of art by stimulated infrared thermography. Eur. Phys. J.-Appl. Phys. 2012; 57 (02): article reference: 21002. http://dx.doi.org/10.1051/epiap/2011110266

[35] Lechner N. Heating, cooling, lighting: Sustainable design methods for architects, 4th Edition, John Wiley and Sons Inc., New York (USA), 1990.

[36] Flores Larsen S, Hongn M. Determining the infrared reflectance of specular surfaces by using thermographic analysis. Renew. Energ. 2014; 64: 306-313. http://dx.doi.org/10.1016/j.renene.2013.11.049

[37] Krenzinger A, de Andrade AC. Accurate outdoor glass thermographic thermometry applied to solar energy devices. Sol. Energ. 2007; 81 (8): 1025-1034. http://dx.doi.org/10.1016/j.solener.2006.11.014

[38] Elmahdy AH, Devine F. Laboratory Infrared thermography technique for window surface temperature measurements. ASHRAE Tran. 2005; 111 (1): 561-571.

[39] Spring RW, Snell JJR. Unique thermal problem found in certain double-glazed windows. In: Proc. SPIE 4710, Thermosense XXIV, eds. X. P. Maldague and A. E. Rozlosnik. Orlando, Florida, USA; 2002: 276-280. http://dx.doi.org/10.1117/12.459575

[40] Pal S, Roy B, Neogi S. Heat transfer modelling on windows and glazing under the exposure of solar radiation. Energ. Buildings 2009; 41 (6): 654-661. http://dx.doi.org/10.1016/i.enbuild.2009.01.003

[41] Brent TG, Elizabeth UF, Mehry Y, Dariush KA. The significance of bolts in the thermal performance of curtain-wall frames for glazed façades. ASHRAE Tran. 1997; 104, Part 1: 1-15.

[42] Mingxuan LI, Guojian LU, Zhongri HU, Xiujuan MEI, Le LI, Liping W. Research on fire endurance of tempered glass based on Infrared imaging technology. Procedia Eng. 2014; 84: 553-557. http://dx.doi.org/10.1016/i.proeng.2014.10.467 
[43] Le Cam J-B, Robin E, Balandraud X, Toussaint E. A new experimental route in thermomechanics of inorganic glasses using infrared thermography. J. Non-Cryst. Solids 2013; 366: 64-69. http://dx.doi.org/10.1016/i.jnoncrysol.2013.01.050

[44] Robin E, Le Cam J-B, Balandraud X, Toussaint E, Brilland L. First steps towards the thermomechanical characterization of chalcogenide glass using quantitative infrared thermography. J. Non-Cryst. Solids 2014; 391: 101-105. http://dx.doi.org/10.1016/j.jnoncrysol.2014.03.015

[45] Yang B, Liaw PK, Wang G, Morrison M, Liu CT, Buchanan RA, et al. In-situ thermographic observation of mechanical damage in bulk-metallic glasses during fatigue and tensile experiments. Intermetallics 2004; 12 (10-11): 1265-1274. http://dx.doi.org/10.1016/i.intermet.2004.04.006

[46] Wen LY. The measurement of temperature distribution of glass plate using Infrared Thermography. In: Proc. SPIE 0780, Thermosense IX: Thermal Infrared Sensing for Diagnostics and Control, eds. R. P. Madding. Orlando, FL, United States: SPIE; 1987: 4. http://dx.doi.org/10.1117/12.940501

[47] Corvec G, Robin E, Le Cam J-B, Sangleboeuf J-C, Lucas P. Improving spatio-temporal resolution of infrared images to detect thermal activity of defect at the surface of inorganic glass. Infrared. Phys. Techn. 2016; 77: 193-202. http://dx.doi.org/10.1016/j.infrared.2016.05.026

[48] Straube H, Breitenstein O. Infrared lock-in thermography through glass substrates. Sol. Energ. Mat. Sol. C 2011; 95 (10): 2768-2771. http://dx.doi.org/10.1016/j.solmat.2011.05.017

[49] Naderi M, Kahirdeh A, Khonsari MM. Dissipated thermal energy and damage evolution of Glass/Epoxy using infrared thermography and acoustic emission. Compos. Part B-Eng. 2012; 43 (3): 1613-1620. http://dx.doi.org/10.1016/i.compositesb.2011.08.002

[50] Meola C, Carlomagno GM. Infrared thermography to evaluate impact damage in glass/epoxy with manufacturing defects. Int. J. Impact Eng. 2014; 67: 1-11. http://dx.doi.org/10.1016/j.ijimpeng.2013.12.010

[51] Ibarra-Castanedo C, González D, Klein M, Pilla M, Vallerand S, Maldague X. Infrared image processing and data analysis. Infrared Phys. Technol. 2004; 46 (1): 75-83. https://doi.org/10.1016/i.infrared.2004.03.011

[52] Edis E, Flores-Colen I, de Brito J. Quasi-quantitative infrared thermographic detection of moisture variation in facades with adhered ceramic cladding using principal component analysis. Build. Environ. 2015; 94 (Part 1): 97-108. https://doi.org/10.1016/i.buildenv.2015.07.027

[53] Di Maio R, Piegari E, Mancini C, Chiapparino A. Quantitative analysis of pulse thermography data for degradation assessment of historical buildings. Eur Phys J Plus 2015; 130 (6): 105. http://dx.doi.org/10.1140/epjp/i2015-15105-6

[54] Lerma JL, Cabrelles M, Portalés C. Multitemporal thermal analysis to detect moisture on a building $\begin{array}{lllll}\text { façade. Constr. } & \text { Build. Mater. 2011; } 25 & \text { (5): } & \text { 2190-2197. }\end{array}$ https://doi.org/10.1016/j.conbuildmat.2010.10.007

[55] Elvidge CD, Keith DM, Tuttle BT, Baugh KE. Spectral identification of lighting type and character. Sensors 2010; 10 (4): 3961. http://dx.doi.org/10.3390/s100403961

[56] Ronda CR. Luminescence: From Theory to Applications, John Wiley \& Sons, Weinheim, Germany, 2008.

[57] Fernández Navarro JM. El vidrio, 3er ed., Editorial CSIC - CSIC Press, Madrid, 2003.

[58] Abo-Naf SM, El Batal FH, Azooz MA. Characterization of some glasses in the system $\mathrm{SiO}_{2}$, $\mathrm{Na}_{2} \mathrm{O} \cdot \mathrm{RO}$ by infrared spectroscopy. Mater. Chem. Phys. 2003; 77 (3): 846-852. http://dx.doi.org/10.1016/S0254-0584(02)00215-8

[59] Delgado J, Vilarigues M, Ruivo A, Corregidor V, Silva RCd, Alves LC. Characterisation of medieval yellow silver stained glass from Convento de Cristo in Tomar, Portugal. Nucl. Instrum. Meth. B 2011; 269 (20): 2383-2388. http://dx.doi.org/10.1016/j.nimb.2011.02.059

[60] Jembrih-Simburger D, Neelmeijer C, Schalm O, Fredrickx P, Schreiner M, De Vis K, et al. The colour of silver stained glass-analytical investigations carried out with XRF, SEM/EDX, TEM, and IBA. J. Anal. Atom. Spectrom. 2002; 17 (4): 321-328. http://dx.doi.org/10.1039/B111024C

[61] Pérez-Villar S, Rubio J, Oteo JL. Study of color and structural changes in silver painted medieval $\begin{array}{llllll}\text { glasses. J. Non-Cryst. Solids 2008; } 354 & \text { (17): } & \text { 1833-1844. }\end{array}$ http://dx.doi.org/10.1016/j.jnoncrysol.2007.10.008

[62] Schalm O. Characterization of paint layers in stained-glass windows: main causes of the degradation of nineteenth century grisaille paint layers, PhD dissertation, Antwerp, 2000.

[63] Caen J. The production of stained glass in the County of Flanders and the Duchy of Brabant from the XVth to the XVIIIth centuries: materials and techniques, Brepols, Belgium, 2009.

[64] Pradell T, Molina G, Murcia S, Ibáñez R, Liu C, Molera J, et al. Materials, techniques, and conservation of historic stained glass "grisailles". Int. J. Appl. Glass Sci. 2016; 7 (1): 41-58. http://dx.doi.org/10.1111/ijag.12125 
[65] Bella ED. Thermographic survey for the preservation and restoration of architectural cultural heritage. In: Handbook of Research on Emerging Technologies for Digital Preservation and Information Modeling, eds. A. Ippolito and M. Cigola. USA: IGI Global; 2016: 91-118. http://dx.doi.org/10.4018/9781-5225-0680-5.ch005

[66] Campa A, Hsieh SJ, Wang HJ. Non-visible defect detection in glass using infrared thermography and artificial neural networks. In: Proc. SPIE 8705, Thermosense: Thermal Infrared Applications XXXV, eds. G. R. Stockton and F. P. Colbert. Baltimore, Maryland, USA; 2013: 87050R (87051-87012). http://dx.doi.org/10.1117/12.2015650 